\title{
Boron Carbide Particle as a Boron Compound for Boron Neutron Capture Therapy
}

Takaki Iwagami $^{1}$, Yoshie Ishikawa ${ }^{2}$, Naoto Koshizaki ${ }^{3}$, Naofumi Yamamoto ${ }^{4}$, Hiroki Tanaka ${ }^{5}$, Shin-ichiro Masunaga ${ }^{5}$, Yoshinori Sakurai ${ }^{6}$, Itsuro Kato ${ }^{1}$, Soichi Iwai $^{1}$, Minoru Suzuki ${ }^{5}$, and Yoshiaki Yura ${ }^{1 *}$

${ }^{1}$ Department of Oral and Maxillofacial Surgery, Osaka University Graduate School of Dentistry, 1-8 Yamadaoka, Suita, Osaka 565-0871, Japan

${ }^{2}$ Nanosystem Research Institute, National Institute of Advanced Industrial Science and Technology, Tsukuba Central 5, 1-1-1 Higashi, Tsukuba, Ibaraki 305-8565, Japan

${ }^{3}$ Research Group of Plasma Science and Engineering, Division of Quantum Science and Engineering, Graduate School of Engineering, Kita13, Nishi8, Kita-ku, Sapporo, Hokkaido 060-8628, Japan

${ }^{4}$ Department of Oral and Maxillofacial Surgery, Osaka Saiseikai Senri Hospital, 1-1-6 Tsukumodai, Suita, Osaka 565-0862, Japan

${ }^{5}$ Particle Radiation Oncology Research Center, Research Reactor Institute, Kyoto University, Asashiro-nishi 2, Kumatori-cho, Sennan-gun, Osaka 590-0494, Japan

${ }^{6}$ Department of Radiation Life Science, Research Reactor Institute, Kyoto University, Asashiro-nishi 2, Kumatori-cho, Sennan-gun, Osaka 590-0494, Japan

"Corresponding author: Yoshiaki Yura, Department of Oral and Maxillofacial Surgery, Osaka University Graduate School of Dentistry, 1-8 Yamadaoka, Suita, Osaka 565-0871, Japan, Tel: +81-6-6987-2941; Fax: +81-6-6879-2170; E-mail: yura@dent.osaka-u.ac.jp

Received date: Apr 16, 2014, Accepted date: Jun 20, 2014, Publication date: Jun 30, 2014

Copyright: (C) 2014 Iwagami T, et al. This is an open-access article distributed under the terms of the Creative Commons Attribution License, which permits unrestricted use, distribution, and reproduction in any medium, provided the original author and source are credited.

\begin{abstract}
Background: In boron neutron capture therapy (BNCT), the intravenous administration of boron-containing compounds such as boronophenylalanine (BPA) and borocaptate sodium (BSH) is followed by irradiation with thermal neutrons. In the present study, we determined whether a boron-rich boron carbide $\left(\mathrm{B}_{4} \mathrm{C}\right)$ nanoparticle could be used for BNCT.

Methods: $\mathrm{B}_{4} \mathrm{C}$ nanoparticles were obtained by the laser fragmentation of boron particles in ethyl acetate. Neutron irradiation was delivered via a neutron beam at the Kyoto University Research Reactor (KUR).

Results: Cell viability was lower in oral squamous cell carcinoma (SCC) cells exposed to neutrons in the presence of $\mathrm{B}_{4} \mathrm{C}$ particles than in those exposed to neutrons only. The combination of $\mathrm{B}_{4} \mathrm{C}$ particles and neutron irradiation also decreased the formation of colonies. Injecting $\mathrm{B}_{4} \mathrm{C}$ particles into the oral SCC xenografts of nude mice increased the concentration of ${ }^{10} \mathrm{~B}$ in the tumors, but not in the kidney, liver, or spleen. The body weights of animals were not affected by neutron irradiation to $\mathrm{B}_{4} \mathrm{C}$-injected tumors. Tumor volumes were lower in the $\mathrm{B}_{4} \mathrm{C}$ mediated BNCT group than in the neutron group.
\end{abstract} CC.

Conclusion: These results indicate that $\mathrm{B}_{4} \mathrm{C}$ particles can be used locally as a boron compound in BNCT for oral

Keywords: Boron neutron capture therapy; Boron carbide; Oral squamous cell carcinoma

\section{Introduction}

Boron neutron capture therapy (BNCT) is a binary modality, in which the intravenous administration of boron containing compounds is followed by irradiation with thermal neutrons. ${ }^{10} \mathrm{~B}$ in tumors absorbs a thermal neutron and releases two high linear energy transfer (LET) particles: an $\alpha\left({ }^{4} \mathrm{He}\right)$ particle and lithium $\left({ }^{7} \mathrm{Li}\right)$ nucleus. These high LET particles have path lengths in water of 5-10 $\mu \mathrm{m}$. Thus, BNCT can selectively destroy tumours, if the concentration of ${ }^{10} \mathrm{~B}$ in tumors can be increased beyond that in normal tissues [1,2].

Boronophenylalanine (BPA) and borocaptate sodium (BSH) have been the only clinically used boron-containing compounds. BPA, a derivative of the amino acid phenylalanine, can be incorporated into tumor cells through specific uptake mechanisms involving the L family of heterodimeric, sodium-independent, amino acid transporters located at the plasma membrane, particularly L-amino acid transported -1 (LAT-1) [3,4], while BSH can permeate the blood-brain barrier for tumor cell in the brain. Difficulties have been associated with labeling of quiescent cells at the G0 phase with BPA $[5,6]$. A difficult expression of LAT-1 and arrest of the cell cycle may be responsible for the failed incorporation of BPA into tumor cells. Moreover, these compounds contain a small amount of boron within their molecules.

The use of nanoscale materials in medicine represents an important research area. Numerous nanoscale materials with various components, morphologies, and sizes have been used in drug delivery, bioimaging, chemical sensing, cancer cell diagnosis, and therapeutics [7-10]. A radiofrequency (RF) field-generating system was combined with single- walled carbon nanotubes, which efficiently acted to convert RF irradiation into heat [7]. Gold nanoparticles are a unique photosensitizer in that they exhibit strong localized surface plasma resonance. These nanoparticles have been directly injected into tumors $[8,10]$. Thereafter, animals received RF treatment or irradiation with near-infrared light and tumors were destroyed by the high temperatures generated. Gadolinium (Gd)-loaded chitosan nanoparticles were used intratumorally in the field of neutron capture therapy (NCT), [11,12]. 
We previously developed a nanoparticle composed of spherical boron carbide $\left(\mathrm{B}_{4} \mathrm{C}\right)$. Each $\mathrm{B}_{4} \mathrm{C}$ particle obtained was encapsulated in a graphitic layer and the initial grain size was approximately $200 \mathrm{~nm}$ $[13,14]$. Since a concentrated amount of boron is required in a tumor cell for high effective $\mathrm{BNCT}$, the application of $\mathrm{B}_{4} \mathrm{C}$ particles with numerous boron atoms may improve the efficiency of this therapy. The intratumoral application of such boron-rich compounds may eradicate BNCT-resistant tumor cells that do not take up BPA. Previous studies reported that BPA-mediated BNCT was effective for the treatment of patients with advanced head and neck cancer $[15,16]$ Head and neck cancer may be a suitable target for $\mathrm{B}_{4} \mathrm{C}$-mediated BNCT because boron compounds can be directly injected into these tumors. In the present study, we determined whether locally administered $\mathrm{B}_{4} \mathrm{C}$ nanoparticles could act as a boron compound for BNCT.

\section{Materials and Methods}

\section{Cell culture}

The human oral SCC cell line SAS was obtained from the Japanese Collection of Research Bioresources (Tokyo, Japan). SAS cells were cultured in Dulbecco's modified Eagle's medium supplemented with $10 \%$ fetal bovine serum, $2 \mathrm{mM} \mathrm{L}$-glutamine, $100 \mathrm{U} / \mathrm{ml}$ penicillin, and $100 \mu \mathrm{g} / \mathrm{ml}$ streptomycin, and were then grown in an incubator at $37^{\circ} \mathrm{C}$ in a humidified atmosphere with $5 \% \mathrm{CO}_{2}$. The cells that grew on plastic dishes were dissociated with $0.05 \%$ trypsin and $0.02 \%$ ethylenediaminetetraacetic acid (EDTA). They were suspended in a microtube with a volume of $1.5 \mathrm{ml}$ and incubated while rotating at $37^{\circ} \mathrm{C}$.

\section{Boron compound and BNCT for cultured cells}

$\mathrm{B}_{4} \mathrm{C}$ particles containing natural boron were prepared as described previously $[13,14]$. The mean diameter of the particles was $200 \mathrm{~nm}$. Each $\mathrm{B}_{4} \mathrm{C}$ particle was encapsulated in a graphitic layer. They were dissolved in phosphate-buffered saline (PBS) and a stock solution was made of $\mathrm{B}_{4} \mathrm{C}$ at a concentration of $1,000 \mathrm{ppm}$.

Regarding in vitro BNCT, SAS cells were dissociated by a treatment with EDTA-trypsin and suspended in $200 \mu \mathrm{l}$ medium containing 50 ppm $\mathrm{B}_{4} \mathrm{C}$ particles in a microtube. These tubes were exposed to thermal neutrons $10 \mathrm{~min}$ later at the Kyoto University Research Reactor (KUR). Neutron fluence was measured based on the radioactivation of gold foil on the front and back of the tubes, as described previously $[17,18]$. The average fluence of the thermal neutrons was $3.10 \times 10^{12} \mathrm{n} / \mathrm{cm}^{2}$ at 1 MW. Thermoluminescent dosimeters were used for gamma-ray dosimetry, and the total gamma ray dose was $0.55 \mathrm{~Gy}$ after irradiation for $40 \mathrm{~min}$. Thermal neutron fluence was converted to a physical dose using the equation, " $\mathrm{D}=\Phi\left(6.93 \times 10^{-14} \times \mathrm{B}+6.78 \times 10^{-14} \times \mathrm{N}\right)+\mathrm{G}$ ".

where $\mathrm{D}=$ physical dose, $\Phi \mathrm{i}=$ neutron fluence $\left(\mathrm{n} / \mathrm{cm}^{2}\right), \mathrm{B}=$ boron concentration (ppm), N=nitrogen concentration (2\%), and $\mathrm{G}=$ gamma-ray dose (Gy).

\section{3-(4,5-dimethylthiazol-2-yl)-2,5-diphenyl-tetrazolium bromide (MTT) assay and colony formation}

After BNCT, cells were centrifuged at $500 \times \mathrm{g}$ for $5 \mathrm{~min}$, suspended in fresh medium, inoculated in 96-well plates, and incubated for $48 \mathrm{~h}$. Ten microliters of a $5 \mathrm{mg} / \mathrm{ml}$ MTT (Sigma, St.Louis, MO) solution was added to each well with $100 \mu \mathrm{l}$ of medium, and cells were incubated at $37^{\circ} \mathrm{C}$ for $4 \mathrm{~h}$. After the addition of $100 \mu \mathrm{l}$ of $0.04 \mathrm{~N} \mathrm{HCl}$ in isopropanol, the plates were mixed thoroughly to dissolve the dark blue crystals and stood at room temperature overnight. The plates were read on a Benchmark Plus microplate spectrophotometer (Bio-Rad Laboratories, Hercules, CA. USA) with a reference wavelength of $630 \mathrm{~nm}$ and test wavelength of $570 \mathrm{~nm}$. Background absorbance at $630 \mathrm{~nm}$ was subtracted from the $570 \mathrm{~nm}$ reading. The values were divided by those of the control and the rate was calculated.

Treated cells were plated onto $60-\mathrm{mm}$ dishes at a cell density that yielded approximately 100 colonies per dish. The cells were incubated for 14 days, fixed in methanol, and stained with $1 \%$ crystal violet. Colonies composed of more than 50 cells were counted and the surviving cell fraction was determined by dividing the colony number of the irradiated culture by that of the unirradiated control culture.

\section{${ }^{10} \mathrm{~B}$ concentration in tumors and organs}

To generate tumors in nude mice, $1 \times 10^{6}$ cells were inoculated subcutaneously into the back of the leg of 5 -week-old female Balb/c nude mice (Clea Japan Inc., Japan). When the tumors reached a suitable size, i.e., $5-10 \mathrm{~mm}$ in diameter, the animals were used in the BNCT experiments. $\mathrm{B}_{4} \mathrm{C}$ particles were diluted to $250 \mathrm{ppm}$, and $50 \mu \mathrm{l}$ of $\mathrm{B}_{4} \mathrm{C}$ solution containing $12.5 \mu \mathrm{g} \mathrm{B}_{4} \mathrm{C}$ particles was infiltrated into tumors to cover the whole tumor volume. The tumor, liver, kidney, and spleen were removed $10 \mathrm{~min}$ later and placed in teflon tubes. ${ }^{10} \mathrm{~B}$ concentrations in these tissues were measured by prompt gamma-ray spectrometry using a thermal neutron guide installed at the KUR [17]. ${ }^{10} \mathrm{~B}$ concentrations were measured twice and the mean values were obtained.

\section{BNCT for oral SCC xenografts in nude mice}

Tumor-bearing animals were given $50 \mu \mathrm{l}$ of $250 \mathrm{ppm} \mathrm{B}_{4} \mathrm{C}$ solution intratumorally. Thereafter, tumors were exposed to thermal neutrons. Control tumors were left untreated. Neutron irradiation was delivered via a neutron beam at $5 \mathrm{MW}$ (thermal neutron mode 00-0011) in the KUR. The mouse was held stationary during the irradiation protocol for $20 \mathrm{~min}$ in a custom-designed acrylic resin box from which the tumor-bearing legs were pulled out through a narrow slit and fixed with adhesive. A LiF thermoplastic plate with a hole that defined the irradiation field was placed on the animal to expose the tumor-bearing leg only to the neutron beam. Neutron fluence was measured from the radioactivation of gold foil ( $3 \mathrm{~mm}$ in diameter, $0.05 \mathrm{~mm}$ thick) placed at the front and back of the tumors $[19,20]$. The average fluence of thermal neutrons was $7.98 \times 10^{12} \mathrm{n} / \mathrm{cm}^{2}$ at $5 \mathrm{MW}$. Thermoluminescent dosimeters were used for gamma-ray dosimetry, and the total gamma ray dose was $0.97 \mathrm{~Gy}$ after irradiation for $20 \mathrm{~min}$. Thermal neutron fluence was converted to a physical dose using the equation " $\mathrm{D}=\Phi(6.93 \times 10-14 \times \mathrm{B}+6.78 \times 10-14 \times \mathrm{N})+\mathrm{G}$ ".

where $\mathrm{D}=$ physical dose, $\Phi=$ neutron fluence $\left(\mathrm{n} / \mathrm{cm}^{2}\right), \mathrm{B}=$ boron concentration (ppm), N=nitrogen concentration (2\%), and $\mathrm{G}=$ gamma-ray dose (Gy). The experiments performed to examine the antitumor effects of BNCT were started at the same time as neutron irradiation. Tumor length (L) and width (W) were measured every 3-4 days. Tumor volume $(\mathrm{V})$ was determined by the formula: $\mathrm{V}=\mathrm{LW}^{2} / 2$. Experimental groups included untreated control, neutron only, and $\mathrm{B}_{4} \mathrm{C}$-mediated BNCT groups. Four tumors in each group were used in an experiment. Repeated data were combined to evaluate tumor volumes and survival rates. Experiments using nude mice were 
Citation: Iwagami T, Ishikawa Y, Koshizaki N, Yamamoto N, Tanaka H, et al. (2014) Boron Carbide Particle as a Boron Compound for Boron Neutron Capture Therapy. J Nucl Med Radiat Ther 5: 177. doi:10.4172/2155-9619.1000177

Page 3 of 5

performed with the approval of the Institute of Laboratory Animals, Osaka University Graduate School of Dentistry.

\section{Statistical analysis}

All values were expressed as the mean $\pm \mathrm{SD}$. ANOVA tests were used to determine the significance of differences in cell viability, the surviving cell fraction, and tumor volume. After significant differences were confirmed, data were analyzed with the unpaired Student's t test. Statistical analyses were performed using the software Statcel3 (OMS, Tokyo, Japan). A value of $\mathrm{P}<0.05$ was considered to be significant.

\section{Results}

\section{Effects of $\mathrm{B}_{4} \mathrm{C}$-mediated BNCT on SAS cells}

The effects of $\mathrm{B}_{4} \mathrm{C}$-mediated $\mathrm{BNCT}$ were examined in cell cultures. When cells were incubated with $\mathrm{B}_{4} \mathrm{C}$ particles for $10 \mathrm{~min}$ and exposed to neutrons in the presence of $\mathrm{B}_{4} \mathrm{C}$ particles, cell viability was decreased to $77 \%$ of the control $48 \mathrm{~h}$ after the treatment (Figure 1). Neutrons alone decreased cell viability to $96 \%$ of the control. A significant difference $(\mathrm{P}<0.01)$ was observed between the neutron and $\mathrm{B}_{4} \mathrm{C}$-mediated BNCT groups (Figure 1). SAS cells were incubated with $\mathrm{B}_{4} \mathrm{C}$ particles as a control, and no significant changes were noted. When the surviving cell fraction was measured from the formation of colonies after neutron irradiation and $\mathrm{B}_{4} \mathrm{C}$-mediated $\mathrm{BNCT}$, the number of colonies was decreased to $79 \%$ and $38 \%$ of the untreated control, respectively (Figure 2). The difference between these groups was significant $(\mathrm{P}<0.01)$.

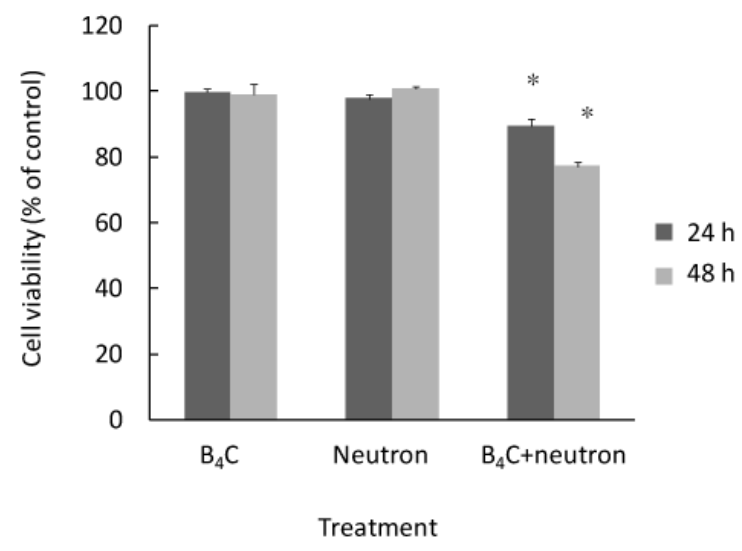

Figure 1: Effects of $\mathrm{B}_{4} \mathrm{C}$-mediated $\mathrm{BNCT}$ on cell viability. SAS cells were incubated in medium containing $\mathrm{B}_{4} \mathrm{C}$ particles at a concentration of $50 \mathrm{ppm}$ for $10 \mathrm{~min}$, and then exposed to thermal neutrons in the presence of $\mathrm{B}_{4} \mathrm{C}$ particles. Cell viability was determined by the MTT assay. ${ }^{*} \mathrm{P}<0.01$ significantly different from cells exposed to neutrons $n=5$.

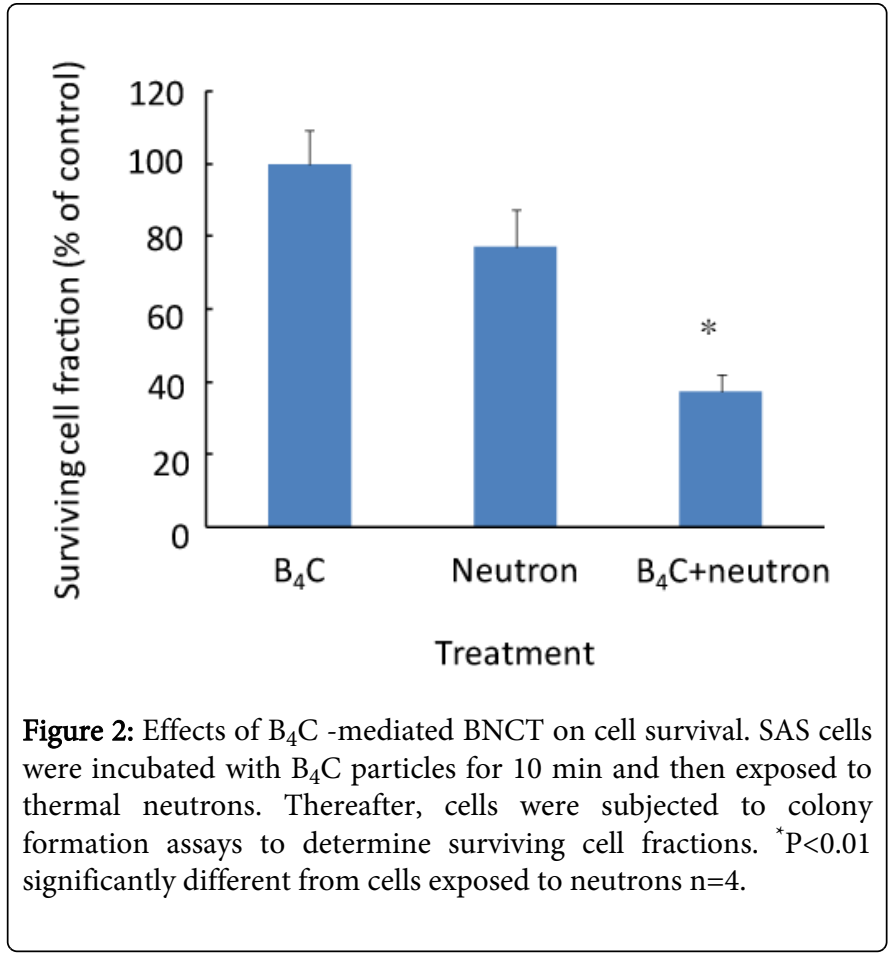

\section{${ }^{10} \mathrm{~B}$ concentrations in oral SCC xenografts in nude mice}

Fifty microliters of $\mathrm{B}_{4} \mathrm{C}$ solution was injected into nude mouse tumours and the ${ }^{10} \mathrm{~B}$ concentration was measured $10 \mathrm{~min}$ later. The ${ }^{10} \mathrm{~B}$ concentration was $18.57 \mathrm{ppm}$ in the tumour, and was less than 1 $\mathrm{ppm}$ in the liver, kidney, and spleen. Using ${ }^{10} \mathrm{~B}$ concentrations in tumours, the physical dose in $\mathrm{B}_{4} \mathrm{C}$-mediated $\mathrm{BNCT}$ was calculated as 13.06 Gy (Table 1).

\begin{tabular}{|l|l|l|}
\hline Group & ${ }^{10} \mathrm{~B}$ concentration (ppm) & Physical dose \\
\hline Neutron & 0 & 2.05 \\
\hline $\mathrm{B}_{4} \mathrm{C}^{+}$neutron & $18.57 \pm 2.66$ & $13.06 \pm 3.63$ \\
\hline
\end{tabular}

Table 1: Boron concentration in tumours and the physical dose.

\section{Effects of $\mathrm{B}_{4} \mathrm{C}$-mediated BNCT on tumour growth in nude mice}

We examined whether $\mathrm{B}_{4} \mathrm{C}$ particles themselves could affect the growth of nude mouse tumours. Three tumours in nude mice received $50 \mu \mathrm{l}$ of $\mathrm{B}_{4} \mathrm{C}$ solution. The mean tumor volume had increased after 14 days and was 7.2-fold higher than that of the initial volume, while the increase in tumour volume in the control group was 7.7-fold. Therefore, no significant difference was observed between the $\mathrm{B}_{4} \mathrm{C}$ particle-treated and control group, which indicated that $\mathrm{B}_{4} \mathrm{C}$ particles did not inhibit the growth of tumours.

To determine the effects of $\mathrm{B}_{4} \mathrm{C}$-mediatd $\mathrm{BNCT}$ on tumour growth, tumour-bearing animals received an intratumoral injection of $\mathrm{B}_{4} \mathrm{C}$ solution followed by neutron irradiation. The experimental groups were as follows: untreated control, neutron only, and $\mathrm{B}_{4} \mathrm{C}$-mediated BNCT. No significant differences were observed in body weight among these groups during the experimental period (Figure 3). Tumours continued to grow and were $5,867 \mathrm{~mm}^{3}$ in control animals 
Page 4 of 5

42 days after the start of the experiment. When tumours were subjected to $\mathrm{B}_{4} \mathrm{C}$-mediated $\mathrm{BNCT}$, tumour volume decreased from 7 days after neutron irradiation. A significant difference was observed between the $\mathrm{B}_{4} \mathrm{C}$-mediated $\mathrm{BNCT}$ and neutron only groups 42 days after BNCT $(\mathrm{P}<0.01)$ (Figure 4$)$.

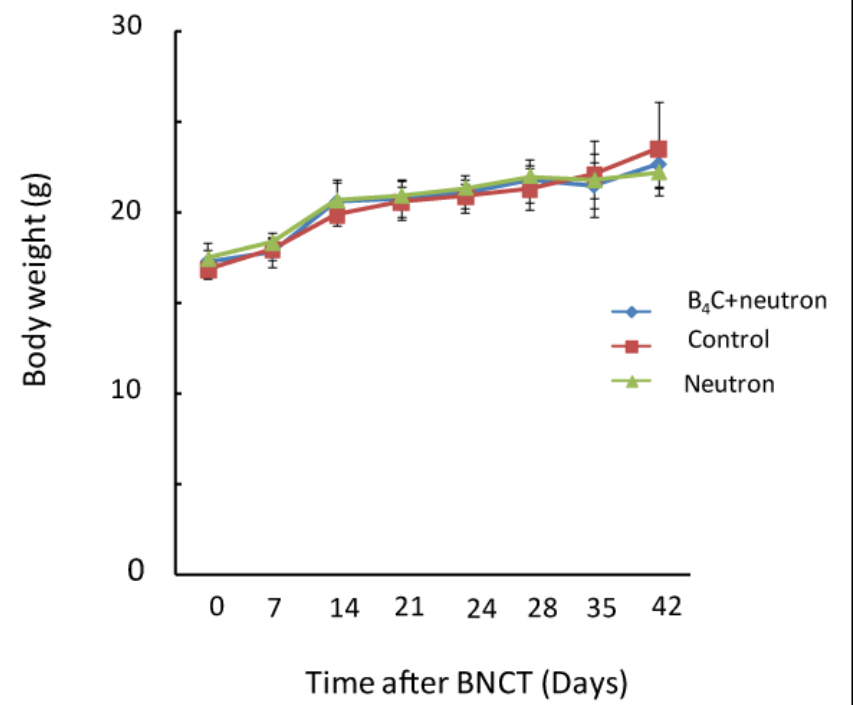

Figure 3: Effects of $\mathrm{B}_{4} \mathrm{C}$-mediated $\mathrm{BNCT}$ on body weight. Nude mice carrying SAS tumors received $50 \mu \mathrm{l}$ of $250 \mathrm{ppm} \mathrm{B}_{4} \mathrm{C}$ solution intratumorally. Ten minutes later, tumors were exposed to thermal neutrons. The experimental groups were as follows: untreated control, neutron only, and $\mathrm{B}_{4} \mathrm{C}$-mediated BNCT. After BNCT, body weight was measured during the experiment $n=5$.

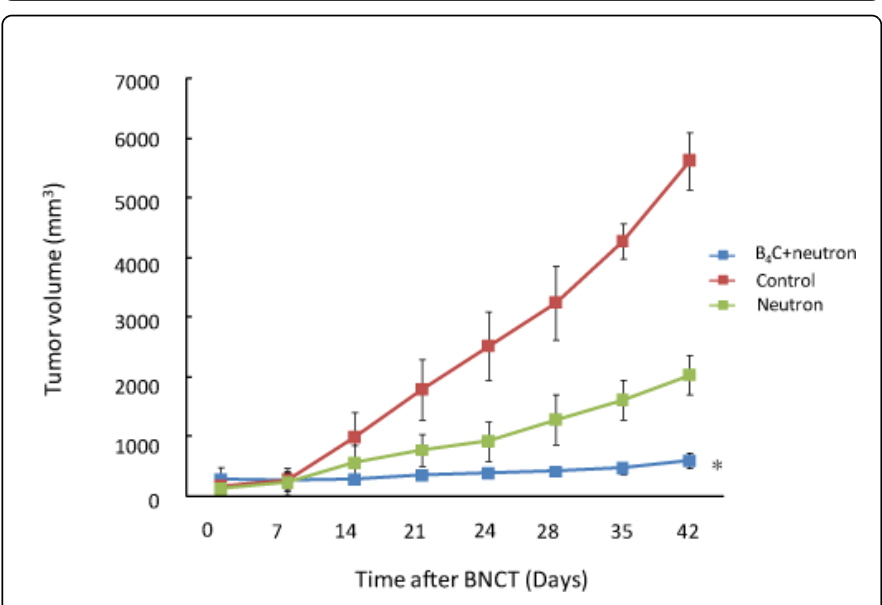

Figure 4: Effects of $\mathrm{B}_{4} \mathrm{C}$-mediated $\mathrm{BNCT}$ on tumour volume. Nude mice carrying SAS tumours were treated as described in Figure 3. After BNCT, tumour size was measured and tumour volume was determined. ${ }^{*} \mathrm{P}<0.01$ significantly different from neutrons only $\mathrm{n}=5$.

The skin on tumours had a normal appearance during the experiment following $\mathrm{B}_{4} \mathrm{C}$-mediated BNCT. No ulceration was observed in any experimental animal until the extensive growth of tumours and necrotic changes occurred.

\section{Discussion}

Tumour cells that retain ${ }^{10} \mathrm{~B}$ are destroyed by the capture of neutrons and production of short-path length particles. BPA is expected to be incorporated into tumour cells by specific uptake mechanisms involving LAT-1 [3,4,21,22]. BSH is not actively incorporated into tumour cells, but enters cells by a concentration gradient. The path lengths of the high LET particles produced by BNCT are in the range of a cell diameter. Therefore, the distance from the boron compound to the cell nucleus is critical.

However, we previously examined the effects of BPA and BSH on oral SCC cells in the presence or absence of these compounds with exposure to neutrons, and demonstrated that an extracellular as well as an intracellular ${ }^{10} \mathrm{~B}$ compound increased the cytotoxicity of BNCT in the cell culture [17]. Although the incorporation of $\mathrm{B}_{4} \mathrm{C}$ particles into tumour cells is not expected because of the grain size and no modification for targeting, extracellular boron-rich $\mathrm{B}_{4} \mathrm{C}$ particles may capture neutrons and destroy tumour cells. To examine this possibility, we performed BNCT in the presence of $\mathrm{B}_{4} \mathrm{C}$ particles and found that cell viability was decreased even though the $\mathrm{B}_{4} \mathrm{C}$ particle itself did not affect the growth of SCC cells. A significant difference was observed between the groups treated with and without $\mathrm{B}_{4} \mathrm{C}$ particles. Colony formation by oral SCC cells was also suppressed by $\mathrm{B}_{4} \mathrm{C}$-mediated $\mathrm{BNCT}$. Thus, it was concluded that $\mathrm{B}_{4} \mathrm{C}$ particles acted as a boron compound for BNCT in cell cultures.

We recently examined the effects of BPA-mediated BNCT on tumours in nude mouse, in which $250 \mu \mathrm{g}$ BPA was administrated intraperitoneally into tumour-bearing mice. Two hours later, the ${ }^{10} \mathrm{~B}$ concentration in tumours was $10.21 \mathrm{ppm}$ and the physical dose was 8.15 Gy. Neutron irradiation to these tumours decreased the tumor volume to $74 \%$ that of tumours treated neutron irradiation only after 42 days [20]. Since the systemic administration of $\mathrm{B}_{4} \mathrm{C}$ particles was considered to be inappropriate, we used $\mathrm{B}_{4} \mathrm{C}$ particles intratumorally at a concentration of $250 \mathrm{ppm}$; the calculated ${ }^{10} \mathrm{~B}$ concentration was $38.94 \mathrm{ppm}$. After injecting $50 \mu \mathrm{B}_{4} \mathrm{C}$ solutions, the measured intratumoral ${ }^{10} \mathrm{~B}$ concentration was $18.57 \mathrm{ppm}$. It is likely that $\mathrm{B}_{4} \mathrm{C}$ particles were retained in the intercellular space of the injected tumours. Based on the ${ }^{10} \mathrm{~B}$ concentration, the physical dose was calculated to be $13.06 \mathrm{~Gy}$. As expected from the attained ${ }^{10} \mathrm{~B}$ concentration, the tumor volume was decreased to $38 \%$ that of tumors treated with neutron irradiation only after 42 days. The difference between $\mathrm{B}_{4} \mathrm{C}$-mediated $\mathrm{BNCT}$ and neutron groups was significant. Thus, the intratumoral injection of $\mathrm{B}_{4} \mathrm{C}$ particles achieved $\mathrm{a}^{10} \mathrm{~B}$ concentration that was sufficient to suppress tumor growth, as observed by BPA-mediated BNCT in which BPA was administrated intraperitoneally. It is likely that boron-rich $\mathrm{B}_{4} \mathrm{C}$ particles localized adjacent to tumor cells may capture neutrons and produce high LET particles to affect cell nucleus.

The effects of $\mathrm{B}_{4} \mathrm{C}$-mediated $\mathrm{BNCT}$ are related to the distribution of the injected $\mathrm{B}_{4} \mathrm{C}$ particles. The amount of $\mathrm{B}_{4} \mathrm{C}$ particles in $50 \mu \mathrm{l}$ solution was $12.5 \mu \mathrm{g}$. In NCT with Gd nanoparticles, a total of $2.4 \mathrm{mg}$ of Gd-nanoCP200 was injected into tumours [12]. "In a non-invasive RF field-generating system", VX2 tumours were injected with $500 \mu \mathrm{g}$ of single-walled carbon nanotubes to destroy tumours [7]. Mice were administrated $50 \mu \mathrm{g}$ of gold nanoflowers intratumorally, followed by irradiation with continuous wave near-infrared light to heat the tumours [10]. Although insoluble agents were retained at the injected site of tumours, this was similar to interstitial radiation therapy using gold seeds. No harmful materials can be kept in the body in exchange for tumour regression. Therefore, $12.5 \mu \mathrm{g}$ of $\mathrm{B}_{4} \mathrm{C}$ particles was used in 
the present study to induce a significant antitumor effect. A high ${ }^{10} \mathrm{~B}$ concentration was achieved in tumours, but not in the liver, kidney, or spleen. Body weight was also unaffected during the experiment. Thus, the side effects of $\mathrm{B}_{4} \mathrm{C}$-mediated $\mathrm{BNCT}$ appear to be minimal.

If $\mathrm{B}_{4} \mathrm{C}$ particles are distributed between the epithelial cells of the covering skin, $\mathrm{B}_{4} \mathrm{C}$-mediated $\mathrm{BNCT}$ may affect the viability of skin as well as tumours [20]. However, we did not observe any skin defects after BNCT in the present study. Although aberrant tumour blood vessels allow $\mathrm{B}_{4} \mathrm{C}$ particles to reach the tumour environment, $\mathrm{B}_{4} \mathrm{C}$ particles do not accumulate in the intracellular space of a normal epithelium following an intratumoral injection. Therefore, skin is not damaged by BNCT.

\section{Conclusions}

We demonstrated that $\mathrm{B}_{4} \mathrm{C}$ particles in combination with neutron irradiation decreased cell viability in cell cultures. The growth of oral SCC xenografts in nude mice was more significantly suppressed with $\mathrm{B}_{4} \mathrm{C}$-mediated $\mathrm{BNCT}$ than with neutron irradiation alone. Therefore, $\mathrm{B}_{4} \mathrm{C}$ particles may be used locally as a ${ }^{10} \mathrm{~B}$ compound in the treatment of oral SCC cells by BNCT.

The authors declare that they have no competing interests.

\section{Acknowledgments}

This study was supported in part by a Grant-in-Aid (No. 23659944) for Scientific Research from the Ministry of Education, Science and Culture of Japan.

\section{References}

1. Coderre JA, Morris GM (1999) The radiation biology of boron neutron capture therapy. Radiat Res 151: 1-18.

2. Barth RF, Coderre JA, Vicente MG, Blue TE (2005) Boron neutron capture therapy of cancer: current status and future prospects. Clin Cancer Res 11: 3987-4002.

3. Campbell WA, Sah DE, Medina MM, Albina JE, Coleman WB, et al. (2000) TA1/LAT-1/CD98 light chain and system L activity, but not 4F2/ CD98 heavy chain, respond to arginine availability in rat hepatic cells. Loss Of response in tumor cells. J Biol Chem 275: 5347-5354.

4. Detta A, Cruickshank GS (2009) L-amino acid transporter-1 and boronophenylalanine-based boron neutron capture therapy of human brain tumors. Cancer Res 69: 2126-2132.

5. Ono K, Masunaga SI, Kinashi Y, Takagaki M, Akaboshi M, et al. (1996) Radiobiological evidence suggesting heterogeneous microdistribution of boron compounds in tumors: its relation to quiescent cell population and tumor cure in neutron capture therapy. Int J Radiat Oncol Biol Phys 34: 1081-1086.

6. Masunaga S, Ono K, Takahashi A, Sakurai Y, Ohnishi K, et al. (2002) Impact of the p53 status of the tumor cells on the effect of reactor neutron beam irradiation, with emphasis on the response of intratumor quiescent cells. Jpn J Cancer Res 93: 1366-1377.
7. Gannon CJ1, Cherukuri P, Yakobson BI, Cognet L, Kanzius JS, et al. (2007) Carbon nanotube-enhanced thermal destruction of cancer cells in a noninvasive radiofrequency field. Cancer 110: 2654-2665.

8. Kobayashi $\mathrm{T}$ (2011) Cancer hyperthermia using magnetic nanoparticles. Biotechnol J 6: 1342-1347.

9. von Maltzahn G1, Park JH, Lin KY, Singh N, Schwöppe C, et al. (2011) Nanoparticles that communicate in vivo to amplify tumour targeting. Nat Mater 10: 545-552.

10. Han J, Li J1, Jia W1, Yao L2, Li X1, et al. (2014) Photothermal therapy of cancer cells using novel hollow gold nanoflowers. Int J Nanomedicine 9: 517-526.

11. Tokumitsu H, Hiratsuka J, Sakurai Y, Kobayashi T, Ichikawa H, et al. (2000) Gadolinium neutron-capture therapy using novel gadopentetic acid-chitosan complex nanoparticles: in vivo growth suppression of experimental melanoma solid tumor. Cancer Lett 150: 177-182.

12. Ichikawa H, Uneme T2, Andoh T2, Arita Y2, Fujimoto T3, et al. (2014) Gadolinium-loaded chitosan nanoparticles for neutron-capture therapy: Influence of micrometric properties of the nanoparticles on tumor-killing effect. Appl Radiat Isot 88: 109-113.

13. Ishikawa Y, Shimizu Y, Sasaki T, Koshizaki N (2007) Boron carbide spherical particles encapsulated in graphite prepared by pulsed laser irradiation of boron in liquid medium. Applied Physics Letters 91: 161110.

14. Ishikawa Y, Sasaki T, Koshizaki N (2010) Submicron-sized boron carbide particles encapsulated in turbostratic graphite prepared by laser fragmentation in liquid medium. J Nanosci Nanotechnol 10: 5467-5470.

15. Kato I, Ono K, Sakurai Y, Ohmae M, Maruhashi A, et al. (2004) Effectiveness of BNCT for recurrent head and neck malignancies. Appl Radiat Isot 61: 1069-1073.

16. Kankaanranta L, Seppälä T, Koivunoro H, Saarilahti K, Atula T, et al. (2007) Boron neutron capture therapy in the treatment of locally recurred head and neck cancer. Int J Radiat Oncol Biol Phys 69: 475-482.

17. Obayashi S, Kato I, Ono K, Masunaga S, Suzuki M, et al. (2004) Delivery of (10)boron to oral squamous cell carcinoma using boronophenylalanine and borocaptate sodium for boron neutron capture therapy. Oral Oncol 40: 474-482.

18. Kamida A, Fujita Y, Kato I, Iwai S, Ono K, et al. (2008) Effect of neutron capture therapy on the cell cycle of human squamous cell carcinoma cells. Int J Radiat Biol 84: 191-199.

19. Fujita Y, Kato I, Iwai S, Ono K, Suzuki M, et al. (2009) Role of p53 mutation in the effect of boron neutron capture therapy on oral squamous cell carcinoma. Radiat Oncol 4: 63.

20. Yamatomo N, Iwagami T, Kato I, Masunaga S, Sakurai Y, et al. (2013) Sonoporation as an enhancing method for boron neutron capture therapy for squamous cell carcinomas. Radiat Oncol 8: 280.

21. Mishima Y, Honda C, Ichihashi M, Obara H, Hiratsuka J, et al. (1989) Treatment of malignant melanoma by single thermal neutron capture therapy with melanoma-seeking 10B-compound. Lancet 2: 388-389.

22. Ferrari C, Bakeine J, Ballarini F, Boninella A, Bortolussi S, et al. (2011) In vitro and in vivo studies of boron neutron capture therapy: boron uptake/washout and cell death. Radiat Res 175: 452-462.
This article was originally published in a special issue, entitled: "Cancer Radiation Therapy", Edited by Xin Chen,University of Arkansas for Medical Sciences, USA 